Ege Tıp Dergisi / Ege Journal of Medicine 2018;57(3):181-183

\title{
Üçüncü trimesterda nadir görülen iniensefali olgusu: Literatür ve yönetim
}

\author{
A rare case of third trimester iniencephaly: Literature and management \\ Sabahattin Anıl Arı Fırat Ökmen İsmet Hortu Ali Akdemir Ahmet Mete Ergenoğlu \\ Ege Üniversitesi Tıp Fakültesi, Kadın Hastalıkları ve Doğum Anabilim Dalı, İzmir, Türkiye
}

Öz

İniensefali, boynun aşırı hiperekstansiyonu ve çeşitli seviyelerde vertebral defektlerle birlikte görülen nadir ve letal bir anomalidir. Nadiren doğan bebekler ise kısa sürede kaybedilirler. Literatürde çok az sayıda uzun dönem yaşayan iniensefali hastası olgu sunumları şeklinde yer almaktadır. Fetal seyirden dolayı ilk trimesterde tanı alan olgular için gebelik terminasyonu önerilmelidir. Bu yazıda takipleri olmayan ve geç tanı alan bir iniensefali olgusu sunulmaktadır.

Anahtar Sözcükler: İniensefali, nöral tüp defekti, prenatal ultrasonografi.

\begin{abstract}
Iniencephaly is a rare, lethal anomaly with spinal retroflexion and multiple defects. Fetuses with iniencephaly, birth uncommonly and die in a short time. In literature, there are few case reports about long live iniencephalic infants. Because of lethal course, termination should be offered. In this report, out of follow-up and late diagnosis case is presented.
\end{abstract}

Keywords: Iniencephaly, neural tube defect, prenatal ultrasonography.

\section{Giriş}

İniensefali, boynun aşırı hiperekstansiyonu ve çeşitli seviyelerde vertebral defektlerle birlikte görülen nadir ve letal bir anomalidir. Saint-Hilaire tarafından 1836 yılında tanımlanmış olup, sıklığı \%0.001-0.01 arasındadır $(1,2)$. Etiyopatogenezi ise bilinmemektedir. Üç temel özelliği şu şekilde sıralanabilir (3):

- Foramen magnumu da içine alan oksipital defekt,

- Tüm omurganın fetüsü yukarı bakışa zorlayan retrofleksiyonu,

- Vakaların yaklaşık \%50'sini etkileyen ve değişik düzeylerde görülebilen açık spinal defektler.

Birçok otör bu nadir anomaliyi bir nöral tüp defekti olarak tanımlamaktadır. Yine ek olarak birçok temel kaynakta ise nöral tüp defektleri konu başlığı altında anlatılmaktadır. Oysaki bu hastalığın bir nöral tüp defekti değil bir gelişim arresti olduğunu vurgulayan yazarlar da vardır (4).

\footnotetext{
Yazışma Adresi: Sabahattin Anıl Arı

Ege Üniversitesi Tıp Fakültesi, Kadın Hastalıkları ve Doğum Anabilim Dalı, İzmir, Türkiye

Makalenin Geliş Tarihi:19.06.2017 Kabul Tarihi: 09.10.2017
}

Bu görüşe göre iniensefali postmenstrüel üçüncü haftada gelişimin durması ve sonucunda servikal fizyolojik retrofeksiyonun persistansı olarak tarif edilir. Bağlantılı olarak nöronal gelişim de başarısızlığa uğrar.İniensefali olguları, olguya ensefalosel eşlik ediyorsa iniensefali apertus, ensefalosel eşlik etmiyorsa iniensefali clausus olarak adlandırılırlar. Hidrosefali, mikrosefali, ventriküler atrezi, holoprosensefali, polimikrogri, serebellar vermis atrezisi, anensefali, düşük kulak, yarık damak/dudak, kardiyak anomaliler, omfolosel, kordon anomalileri, diafragma hernisi, gastrointestinal defektler, renal malformasyonlar, üst ekstremitenin alta kıyasla göreceli büyük oluşu ile birlikte görülebilir (5).

Nadiren doğan bebekler ise kısa sürede kaybedilirler. Literatürde diğer iniensefalik yeni doğanlarda olduğu gibi birkaç saat içinde kaybedilmeyen altı olgu yer almaktadır. Aytar ve ark. (6), iki yaşındaki olgularını yedinci uzun dönem yaşayan iniensefalik bebek olarak bildirmişlerdir. Literatürde genç erişkin döneme ulaşabilen vakalar mevcuttur. Bu vakalar anomalinin hafif formlarıdır ve düzeltici cerrahiler geçirmişlerdir (7).

Erken tanı ve gebeliğin terminasyonu en yakın zamanda planlanmalıdır. 


\section{Olgu Sunumu}

Kırk yaşında, gravida 2 parite 1 , sezaryen öyküsü olan ve son adet tarihine göre 33 hafta 0 gün gebe kliniğimize başvurdu. Takip altında olmayan hastanın ultrasono-grafisinde fetal başın aşırı hiperekstansiyonda, fetal kraniumda posterior fossanın geniş, fetal boynun silinmiş olduğu ve serebellar vermisin izlenmediği belirlendi. Fetusa ait kardiyak ve renal patolojik görünüm saptanmadı. Ayrıca fetal ayaklarda bilateral pes ekinovarus deformitesi izlendi (Şekil-1A,B). İleri gebelik haftası sebebiyle terminasyon seçeneği sunulamayan hastaya iniensefali ön tanısıyla takip önerildi. Hastanın öyküsünde bu gebeliği esnasında herhangi bir merkeze takibe gitmediği, ilk gebeliği ve doğumu ile ilgili herhangi bir problem olmadığı öğrenildi. Soy geçmişinde ise akraba evliliği veya genetik açıdan bilinen bir hastalığının olmadığı bilgisine ulaşıldı. Olgu bir hafta sonra su gelişi yakınmasıyla ile acil servise başvurdu. Değerlendirme sırasında ekstremite gelişi tespit edilen; spontane, tekrarlayan geç deselerasyonları olan hasta acil sezaryen ile doğuma alındı. $1500 \mathrm{~g}$ canlı kız bebek doğurtuldu ve yeni doğan hekimleri tarafından canlandırma uygulandı. Yeni doğanın başının aşııı hiperekstansiyonda ve sırta yapışık olduğu izlendi. Ayaklarında ise pes equinovarus deformitesi fark edildi (Şekil-1.C).

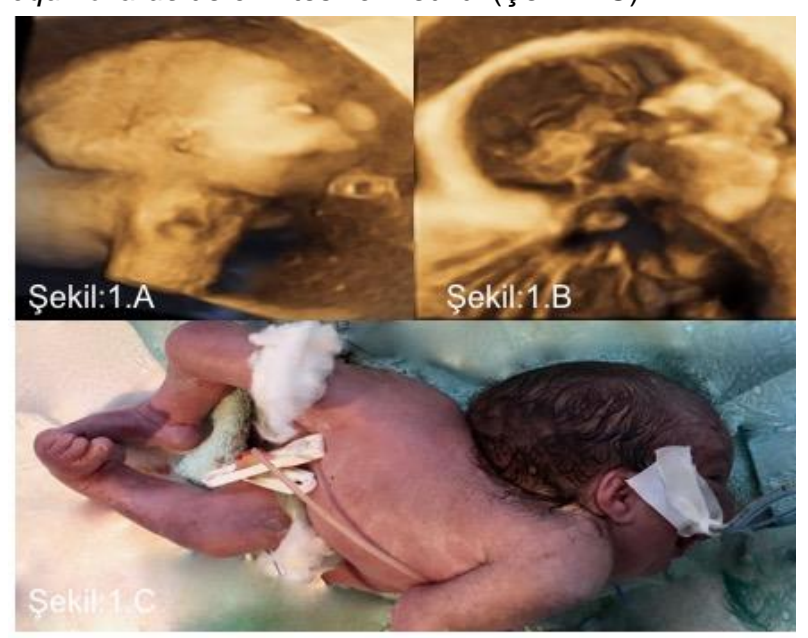

Şekil-1. İniensefali olgusunun ultrasonografik (A, B) ve doğum sonrası (C) görüntüleri.
Hava yolunun sağlanması ve stabilizasyonun temin edilmesinden sonra yeni doğan yoğun bakım ünitesine transfer edildi. Yeni doğanda yapılan manyetik rezonans ve bilgisayarlı tomografi görüntülemelerinde, prenatal olarak gerçekleştirilen ultrasonografide saptanan anomaliler saptandı. Ek kranial, kardiyak ve renal anomaliler saptanmadı.

Hastanın yasal vasisinden tıbbi verilerinin yayınlanabileceğine ilişkin yazıı onam belgesi alındı.

\section{Tartışma}

Nedeni anlaşılamamış olsa da bu nadir anomali kız fetuslarda 9 kat daha sık görülmektedir. Riski artıran etmenler ise düşük sosyoekonomik düzey, obezite, kemoterapik ilaçlar, folik asit eksikliği, sülfonamidler ve tetrasiklin olarak sıralanabilir (8). Yineleme riski ise literatürde $\% 5$ olarak yer almaktadır ve aileler bu konuda bilgilendirilmelidir (9).

Gri-skala ultrasonografide servikal vertebraların hiperekstansiyonu ile birlikte göğüs ile devamlılık gösteren çene ve yüz (tipik hayalci veya stargezer fetüs), genişlemiş foramen magnum, oksipital kemik defekti ve defektif omurların füzyonu izlenebilir (1).

Ön tanılarda ise Klippel Feil sendromu, anensefali ve meningomyelosel dikkate alınmalıdır (8). Ayrımda anahtar nokta ise iniensefalide servikal hiperekstansiyon olmasıdır. Bu özellik diğer anomalilerde yoktur. En dikkat edilmesi gereken nokta ise Klippel Feil ayrıcı tanısı olarak gözükmektedir. Çünkü servikal vertebrada füzyon anomalisi ile birlikte izlenen bu sendrom letal değildir ve cerrahi tedavi şansı vardır (10).

Aytar ve ark. kendi vaka sunumlarında literatürde uzun dönem yaşayan altı hastadan bahsetmektedir. Birçok olgu tanı alarak termine edilmekte, ölü doğmakta veya doğduktan hemen sonra kaybedilmektedir.

Fetal seyirden dolayı ilk trimesterde tanı alan olgular için gebelik terminasyonu önerilmelidir. Daha geç tespit edilen vakalar için ise doğum beklenmelidir. Anatomik kusurdan dolayı yüz geliş görülebileceği için acil sezaryen yerine elektif operasyon planlanmalıdır. 


\section{Kaynaklar}

1. Gadodia A, Gupta P, Sharma R, Kumar S, Gupta G. Antenatal sonography and MRI of iniencephaly apertus and clausus. Fetal Diagn Ther 2010;27(3):178-80.

2. Ceylaner G, Ceylaner S, Günyeli I, Ekici E, Celasun B, Danişman N. Evaluation of 2407 fetuses in a Turkish population Prenatal Diagnosis 2007;27(9):800-7.

3. JoóJG, Beke A, Papp C, Szigeti Z, Csaba A, Papp Z. Major diagnostic and pathological features of iniencephaly based on twenty-four cases. Fetal Diagn Ther 2008;24(1):1-6.

4. Aleksic S, Budzilovich G, Greco MA, Feigin I, Epstein F, Pearson J. Iniencephaly: A neuropathologic study. Clin Neuropathol 1983;2(2):55-61.

5. Seckin KD, Kadirogullari P, Yucel B, Karaaslan O, Yildirim G. An iniencephaly case diagnosed in the first trimester and review of the literature. İKSST Derg 2016;8(1):61-4.

6. Aytar MH, Dogulu F, Cemil B, Ergun E, Kurt G, Baykaner K. Iniencephaly and long-term survival: A rare case report. Childs Nerv Syst 2007;23(6):719-21.

7. Katz VN, Arthur S, Aylsworth, Albright SG. Ininencephaly is not uniformly fatal. Prenat Diagn 1989;9(8):595-9.

8. Tugrul S, Uludoğan M, Pekin O, Uslu H, Celik C, Ersan F. Iniencephaly: Prenatal diagnosis with postmortem sings. J Obstet Gybocol 2007;33(4):566-9.

9. Jayant K, Mehta A, Sanghvi LD. A study of congenital malformations in Mumbai. J Obstet Gynaecol India 1961;11(1):28094.

10. Ercan F, Sarıkaya M, Pekin AT, Sarıkaya S, Acar A. İnieensefali clausu: Olgu Sunumu Bozok Tıp Derg 2017;7(1):88-91. 